\title{
Temperature field distribution of kiln tail of cement preclinkering technology
}

\author{
Xu Xun ${ }^{1,2, a}$ and Wang Lan ${ }^{1, b}$ \\ ${ }^{1}$ Country State Key Laboratory of Green Building Materials, China Building Materials Academy, \\ Beijing 100024, China \\ ${ }^{2}$ Country State Key Laboratory Cultivation Base for Nonmetal Composite and Functional Materials, \\ Southwest University of Science and Technology, Mianyang, Sichuan 621010, PR China \\ a15550045@qq.com, bwanglan@cbmamail.com.cn
}

Keywords: cement preclinkering technology; temperature field distribution; kiln tail

\begin{abstract}
If the temperature of raw meal to feed into rotary kiln is increased from $900{ }^{\circ} \mathrm{C}$ to $1000 \sim 1200^{\circ} \mathrm{C}$, the solid phase reaction and liquid sinter reaction will be significant enhanced, which will help increase clinker production significantly. Through calcinations condition comparison, this paper studied characteristics of temperature field distribution of kiln tail of cement preclinkering technology. Some results are found by system study. The ratio of tail coal of cement preclinering technology is about $70 \%$, raw meal temperature can reach $1070^{\circ} \mathrm{C}$, and flue gas temperature of $\mathrm{C} 1$ is still about $290^{\circ} \mathrm{C}$.
\end{abstract}

\section{Introduction}

Since Aspdin obtained for cement invention patent in 1824, human beings began to use cement as the main building material of the era at large scale. Lasting nearly two hundred years, cement process equipment also changed. Cement kiln developed from vertical kiln, rotary kiln, preheater kiln to predecomposition kiln, far into the ecological environment type to meet the requirements of environmental protection.

Predecomposition kiln technology has been the mainstream of cement clinker calcinations one over the past decades. However, as a bottleneck, the residual decomposition of calcium carbonate and the slowly temperature rising process in rotary kiln limit capacity growing and energy consumption reducing. The rates of heat transfer and need for the clinker burning is hugely imbalanced, which is the main contradiction.

According to the previous research, if the temperature of raw meal to feed into rotary kiln is increased from $900^{\circ} \mathrm{C}$ to $1000 \sim 1200^{\circ} \mathrm{C}$, the solid phase reaction and liquid sinter reaction will be significant enhanced [1-3]. In other words, the above process of enhancing the calcinations for raw meal in preclinkering furnace takes advantages of more efficient heat transfer under the suspension state, and the results are certificated to help increase the clinker production significantly.

Through calcinations condition comparison, this paper showed a new type technology which called cement preclinkering technology [4]. And it is studied that characteristics of temperature field distribution of cyclone preheater and preclinkering furnace systems of cement preclinkering technology.

\section{Concept of cement preclinkering technology}

The process route of preliminary idea for cement preclinkering technology is shown in Figure 1.Firstly raw meal enters the preheater systems, and through multistage (four or five stages) gas-solid heat transfer inside cyclone preheaters, raw meal is preheated to $700 \sim 800^{\circ} \mathrm{C}$. Raw meal enters the preclinkering furnace for chemical reaction and heat transfer, and after the last gas-solid separation inside high temperature cyclone preheater, raw meal temperature obtains $1000 \sim 1200^{\circ} \mathrm{C}$. Then raw meal immediately enters shorter rotary kiln $(L / D=8 \sim 10)$, in which clinker solid phase and liquid sinter 
process react during about 1000/1200 1450 1350 C. Lastly, clinker goes into cooler, then is gone out of that.

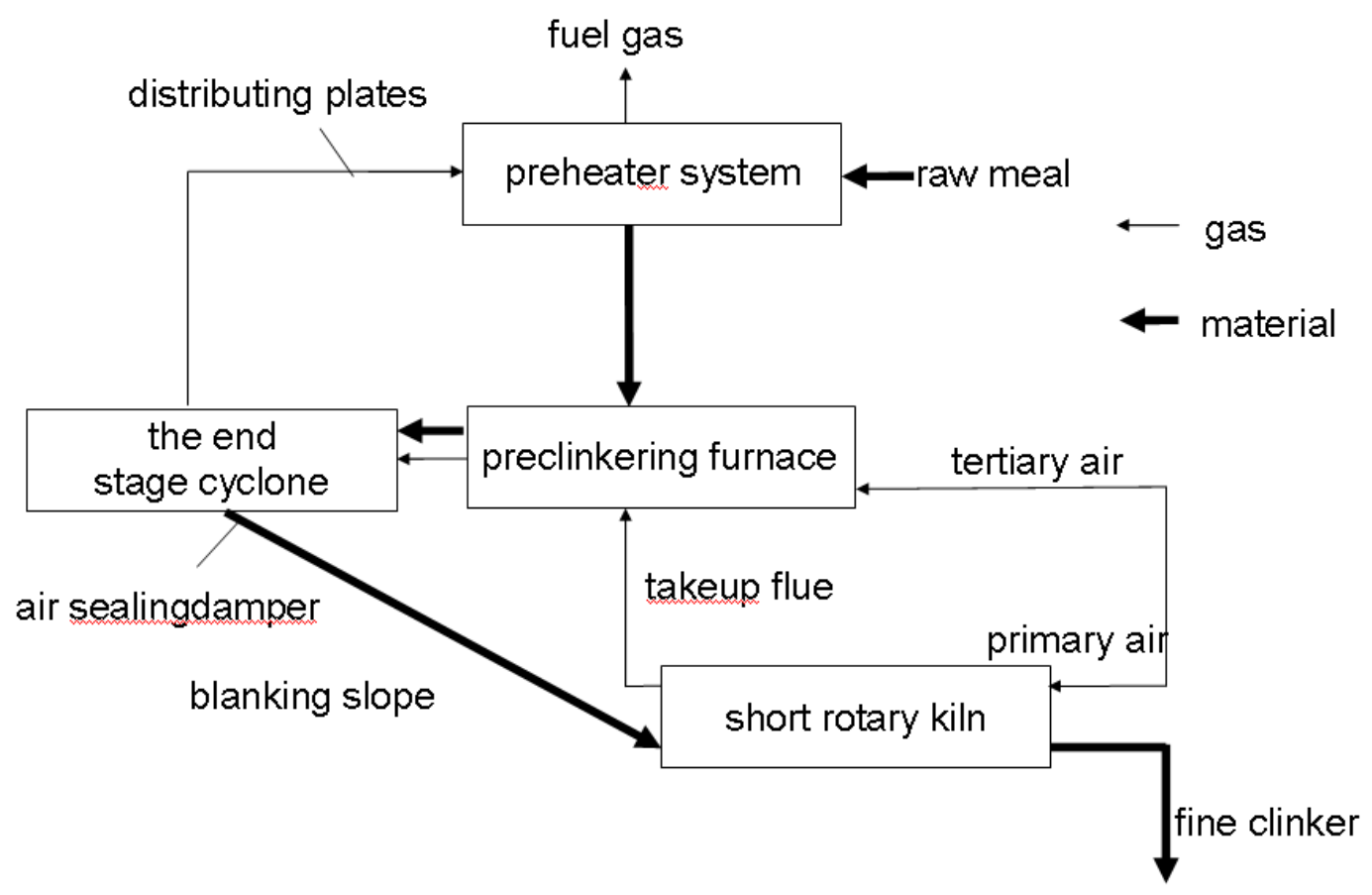

Fig.1 Concept of cement preclinkering technology process

\section{Computational models}

A schematic of preheater unit considered for developing computational model is shown in Figure 2.

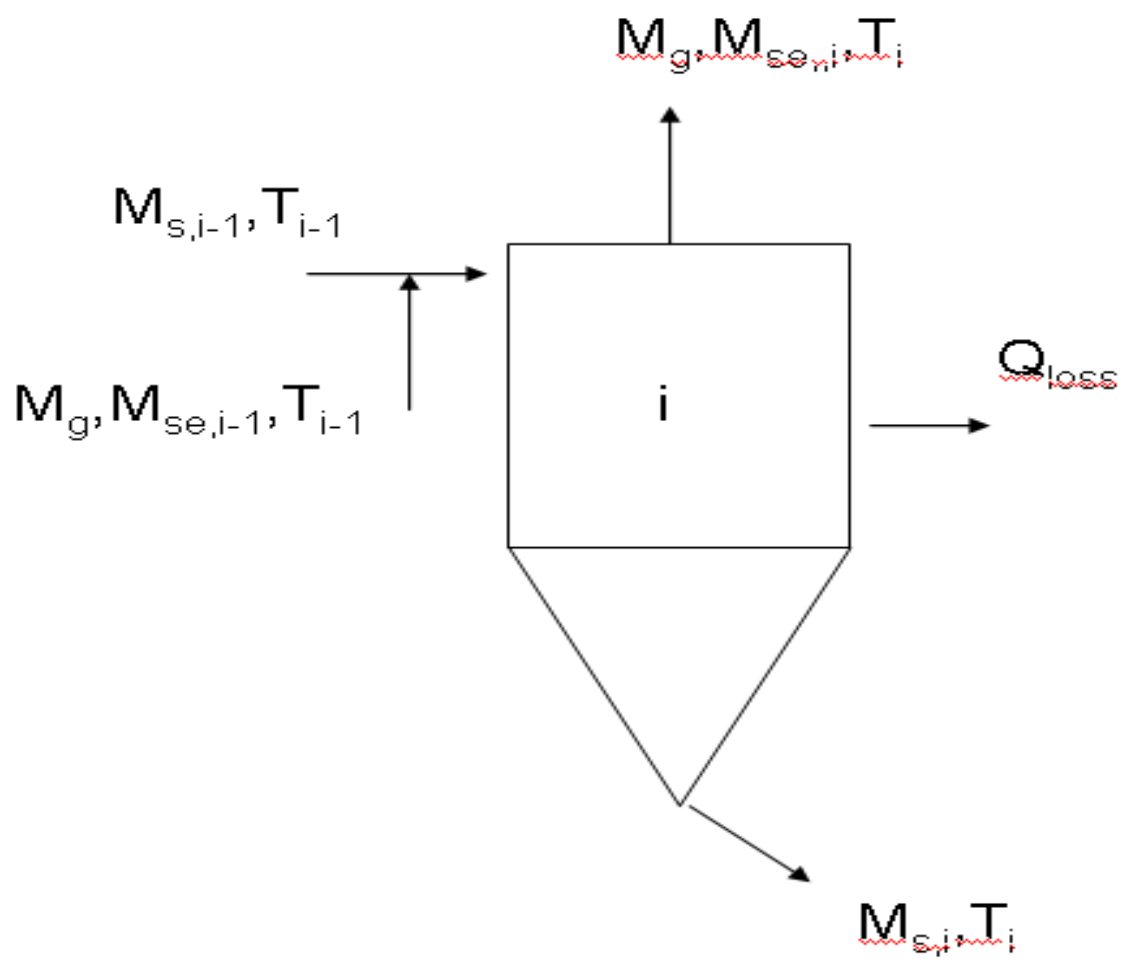

Fig. 2 Schematic of cement preheater 
The gas phase and solids in a cyclone is assumed to be completely mixed. In Fig. 2, Ms is the mass of solids entering the cyclone. $\mathrm{Mg}$ is the mass of the air entering the cyclone. Mse is the mass of solids entrained from a cyclone.

Thus, for any ith cyclone in preheater assembly the following inlet streams are considered:

1. Solids from the (i-1) th cyclone $\left(\mathrm{M}_{\mathrm{s}, \mathrm{i}-1}\right.$ at temperature $\left.\mathrm{T}_{\mathrm{i}-1}\right)$.

2. Solids that are entrained by gas from (i-1)th cyclone $\left(M_{s e, i-1}\right.$ at temperature $\left.T_{i-1}\right)$.

3. Air from (i+1)th cyclone $\left(\mathrm{M}_{\mathrm{g}}\right.$ at temperature $\left.\mathrm{T}_{\mathrm{i}+1}\right)$.

The outlet streams for this cyclone are:

1. Solids going out of cyclone $\left(\mathrm{M}_{\mathrm{s}, \mathrm{i}}\right.$ at temperature $\left.\mathrm{T}_{\mathrm{i}}\right)$.

2. Solids that are entrained by gas $\left(\mathrm{M}_{\mathrm{se}, \mathrm{i}}\right.$ at temperature $\left.\mathrm{T}_{\mathrm{i}}\right)$.

3. Air going out $\left(\mathrm{M}_{\mathrm{g}}\right.$ at temperature $\left.\mathrm{T}_{\mathrm{i}}\right)$.

The steady state material balance equation for ith cyclone is written as

$\mathrm{M}_{\mathrm{s}, \mathrm{i}-1}+\mathrm{M}_{\mathrm{se}, \mathrm{i}-1}=\mathrm{M}_{\mathrm{s}, \mathrm{i}}+\mathrm{M}_{\mathrm{se}, \mathrm{i}}$

$\mathrm{M}_{\mathrm{se}, \mathrm{i}}=(1-\eta) \times \mathrm{M}_{\mathrm{s}, \mathrm{i}-1}$

Mse,i $=(1-\eta) \times M_{s, i-1}$

In the above equations $\eta$ represents the particle capture efficiency of the ith cyclone. $M$ represents the mass of the solids (in $\mathrm{kg} / \mathrm{s}$ ) and subscripts $\mathrm{s}$ and se represent solids and entrained solids, respectively, as explained earlier.

The steady state energy balance for the ith cyclone is written as

$\mathrm{M}_{\mathrm{s}, \mathrm{i}-1} \cdot \mathrm{C}_{\mathrm{p}, \mathrm{s}} \cdot \mathrm{T}_{\mathrm{c}, \mathrm{i}-1}+\mathrm{M}_{\mathrm{se}, \mathrm{i}-1} \cdot \mathrm{C}_{\mathrm{p}, \mathrm{s}} \cdot \mathrm{T}_{\mathrm{c}, \mathrm{i}-1}+\mathrm{M}_{\mathrm{g}} \cdot \mathrm{C}_{\mathrm{p}, \mathrm{g}} \cdot \mathrm{T}_{\mathrm{c}, \mathrm{i}-1}=\mathrm{M}_{\mathrm{s}, \mathrm{i}} \cdot \mathrm{C}_{\mathrm{p}, \mathrm{s}} \cdot \mathrm{T}_{\mathrm{c}, \mathrm{i}}+\mathrm{M}_{\mathrm{se}, \mathrm{i}} \cdot \mathrm{C}_{\mathrm{p}, \mathrm{s}} \cdot \mathrm{T}_{\mathrm{c}, \mathrm{i}}+\mathrm{M}_{\mathrm{g}} \cdot \mathrm{C}_{\mathrm{p}, \mathrm{g}} \cdot \mathrm{T}_{\mathrm{c}, \mathrm{i}}+$ Qloss,i (3)

In the above $C_{p, s}$ and $C_{p, g}$ represents the specific heat of solids and air, respectively. Subscript $g$ represents the air and $\mathrm{T}_{\mathrm{c}, \mathrm{i}}$ represents the temperature of solids and air in the ith cyclone. Qloss,i represents the heat losses for ith cyclone through outer walls.

Mathematics model of preclinkering furnace is similar.

\section{Solution methodology}

Material (solid phase and gas) balance is firstly calculated using relevant known parameter, for example typical feed coal ratio (tail coal: head coal $=60 \%: 40 \%$ ). Then, material distribution data of each unit is obtained. On these basis, heat balance equation of each level cyclone cylinder as a heat exchange unit is listed. Heat balance equation of preclinkering furnace is separately set up. So, seven heat balance equations are totally established. There are seven unknowns in system of equations (outlet gas temperature of every level cyclone and preclinkering furnace). But, specific heat c is a function of temperature T. And outlet material temperature of every level cyclone and preclinkering furnace is decided by gas-solid temperature difference. Therefore the system of equations can be transformed into nonlinear system of equations. For solving the nonlinear system of equations, numerical method is required.

The initial value of simplified linear system of equations is obtained through using the Gauss elimination method. Then the initial value is used in the nonlinear system of equations. Last, the nonlinear system of equations is solved by Newton iterative method.

\section{Results and discussion}

Through the material balance and heat balance calculation, characteristics of temperature field distribution of cement preclinkering technology and cement predecomposition technology in the contrast are shown in Figure 3. 


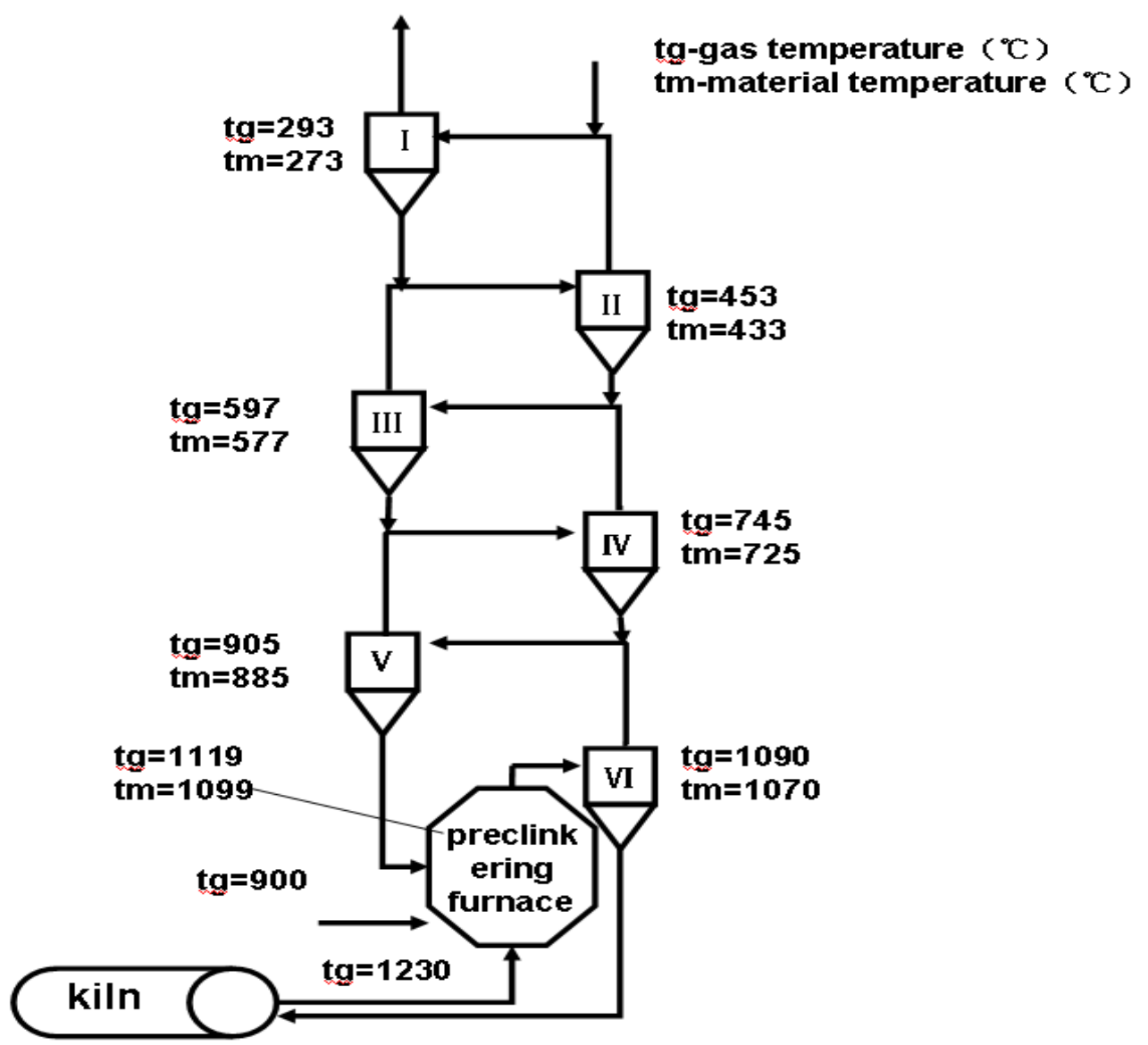

(a) Cement preclinkering technology

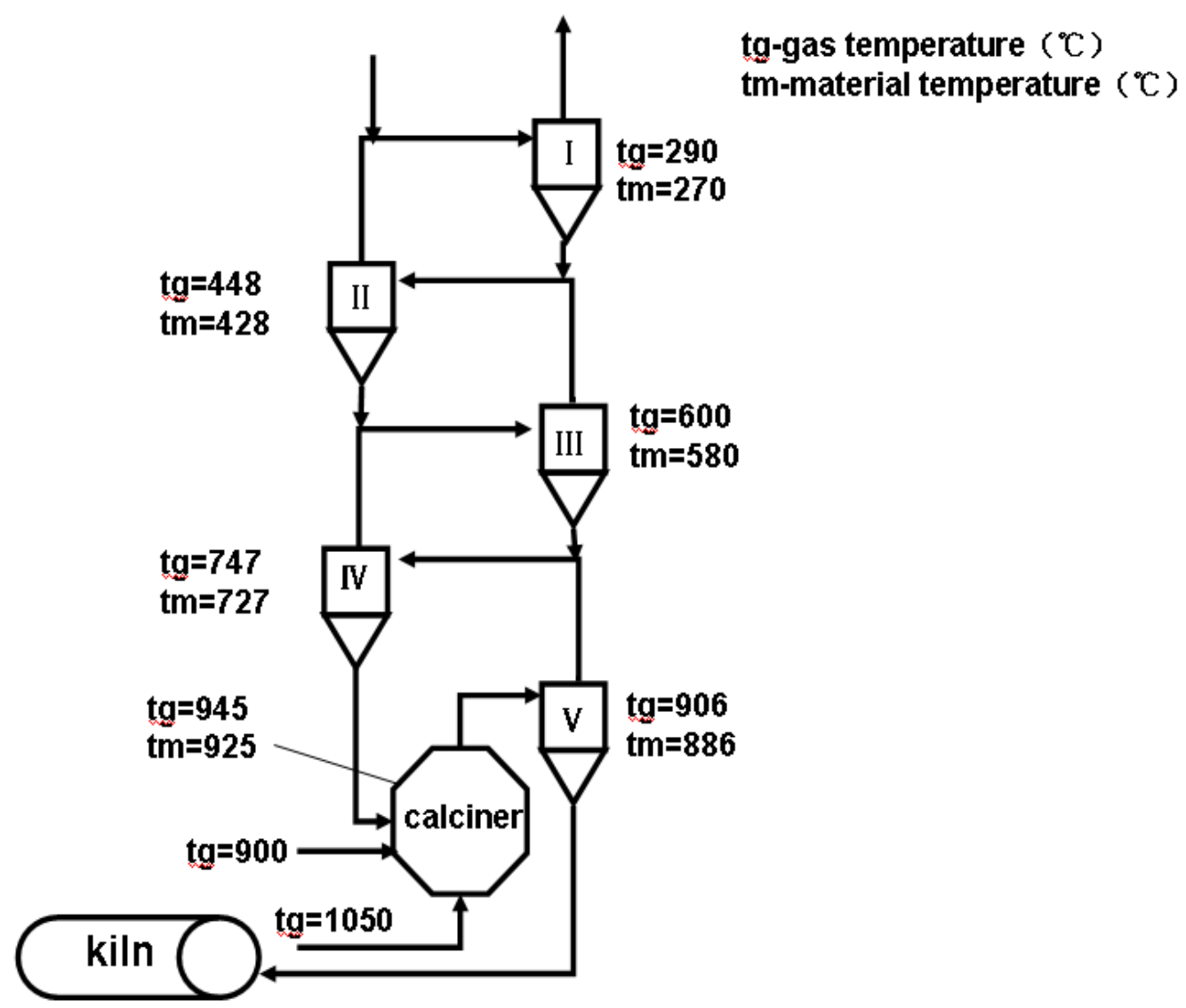

(b) Cement predecomposition technology

Fig.3 The contrast of two systems - gas temperature and material temperature 
As is shown in Fig.3, when the ratio of tail coal of cement preclinkering technology is about $70 \%$, flue gas temperature of $\mathrm{C} 1$ cylinder of cement preclinkering technology is higher than that of cement predecomposition technology, varying from $290^{\circ} \mathrm{C}$ to $293^{\circ} \mathrm{C}$ and increasing $3^{\circ} \mathrm{C}$. But, raw meal temperature into rotary kiln of cement preclinkering technology is higher than that of cement predecomposition technology, varying from $886^{\circ} \mathrm{C}$ to $1070^{\circ} \mathrm{C}$ and increasing $184^{\circ} \mathrm{C}$, which is shown more fully gas-solid heat transfer.

At the same time, because of the existence of large particles and short residence time $(10 \sim 20 \mathrm{~s})$ under the suspended state, raw meal from preclinkering fumace will keep few without decomposition, which is beneficial for stabling temperature inside preclinkering furmace.

Because one level preheater is added in cement preclinkering technology, thermal efficiency of kiln tail system increases from $78.1 \%$ to $80.2 \%$

\section{Conclusion}

The ratio of tail coal of cement preclinkering technology is about $70 \%$, and raw meal temperature can reach $1070^{\circ} \mathrm{C}$. Flue gas temperature of $\mathrm{C} 1$ increased $3^{\circ} \mathrm{C}$, varying from $290^{\circ} \mathrm{C}$ to $293^{\circ} \mathrm{C}$. Raw meal temperature into the kiln increases $184^{\circ} \mathrm{C}$, varying from $886^{\circ} \mathrm{C}$ to $1070^{\circ} \mathrm{C}$.

\section{Acknowledgements}

This paper is supported by National 973 plan project "Low energy consumption cement preparation and application of basic research" subject 2 "Clinker segmented sintering kinetics and process control" (Number: 2009CB623102) and Key fund project of Sichuan provincial department of education "Research on cement rotary kiln heat transfer mathematical model for numerical simulation and energy saving optimization"(Number: 14ZA0086 ).

\section{References}

[1] Zhou yongkang, Strengthen predecomposition and the production of rotary kiln, Cement report of New Century. 4(2000)26-27.

[2] Chen xiaodong, Gao zongyu, Discussion on cement clinker production of rotary kiln by the new dry method, Cement of China. 4(2004)41-42.

[3] Zhaoyimin, Discussion on cement clinker calcining system material preclinkering of the two-level decomposition and its process, Cement of China. 7(2012)45-48.

[4] Wang lan, Wang jiezeng,Tong guishan and Xie jiyou, A method of cement preclinkering production and its system, China Patent 200710147564.8 (2007) 